\title{
Synergistic Action of $\beta$-Glucan and Platelets on Interleukin-8 Production by Human Peripheral Blood Leukocytes
}

\author{
Tatsuya Suzuki, ${ }^{a, b}$ Aiko Tsuzuki, ${ }^{a}$ Naohito Ohno, ${ }^{* a}$ Yukio Ohshima,,${ }^{b}$ Yoshiyuki Adachi, ${ }^{a}$ and \\ Toshiro YADOMAE ${ }^{a}$ \\ Laboratory for Immunopharmacology of Microbial Products, School of Pharmacy, Tokyo University of Pharmacy and Life \\ Science, ${ }^{a}$ Hachioji, Tokyo 192-0392, Japan and Laboratory of Microbiology, Hatano Research Institute, Food and Drug \\ Safety Center, ${ }^{b}$ Hadano, Kanagawa 257-8523, Japan. $\quad$ Received August 13, 2001; accepted September 26, 2001
}

\begin{abstract}
The effects of human platelets on interleukin (IL)-8 production from human peripheral blood mononuclear cells (PBMCs) and polymorphonuclear leukocytes (PMNs) stimulated with the fungal $(1 \rightarrow 3)$ - $\beta$-D-glucan schizophyllan (SPG) were examined using ELISA. PBMCs/PMNs in the presence of platelets and SPG enhanced IL-8 production in comparison with those in the presence of either platelets or SPG. IL-8 production was dependent on the concentration of platelets and incubation time, and the activity reached the maximal level at $18 \mathrm{~h}$ of incubation. These activities were also observed with the addition of platelets prestimulated with SPG to PBMCs. Addition of SPG directly enhanced expression of P-selectin on platelet membrane surfaces. These results suggest that platelets play a key role in the cytokine production of leukocytes induced by fungal $(1 \rightarrow 3)$ - $\beta$-D-glucans and might be mediated, at least in part, by P-selectin.
\end{abstract}

Key words schizophyllan (SPG); P-selectin; interleukin (IL)-8; phagocytosis; glucan receptor

$\beta$-D-Glucans are major structural components of the fungal cell wall and mainly consist of $(1 \rightarrow 3)$-linked and $(1 \rightarrow 6)$ linked $\beta$-D-glucopyranosyl residues. ${ }^{1,2)}$ The ratio of $(1 \rightarrow 3)$-/ $(1 \rightarrow 6)$-linkages and architecture of the $\beta$-glucan network vary significantly depending on the species as well as specimens, such as from mycelium, fruit body, and yeast. It is well known that fungal $(1 \rightarrow 3)$ - $\beta$-D-glucans exhibit various immunomodulating activities, such as antitumor activity, adjuvant activity, hematopoietic activity, complement activation, and cytokine production. ${ }^{3-8)}$ We have been studying the relationship between the structure and activity of fungal $\beta$-glucans and suggested that the activity of $\beta$-glucan was significantly different depending on the molecular weight, degree of branching, solubility, and conformation. Even though $\beta$ glucans are the major component of the fungal cell wall, the structure and content of immunomodulating $\beta$-glucans are also significantly different depending on the species and specimens. It is difficult to discriminate between the immunomodulating versus inert $\beta$-glucans in fungi, and $\beta$-glucans may show a variety of immunomodulating spectra. On the other hand, $(1 \rightarrow 3)$ - $\beta$-D-glucans are detected in the sera of patients with systemic fungal infections and are clinically approved for the diagnostic limulus $G$ test. ${ }^{9)}$ Recently, several investigators have suggested the presence of the $\beta$-glucan receptor on human monocytes and murine peritoneal macrophages, and these proteins could be candidates for the functional $\beta$-glucan receptor. ${ }^{10-12)}$ However, this is not sufficient to understand the entire mechanism of $\beta$-glucan mediated biological activity because of the diversity of $\beta$-glucanmediated activity.

Platelets are anucleate blood cells that are required for hemostasis and they participate in pathologic thrombotic syndromes. Platelets are one of the primary defense barriers against the invasion of bacteria and fungi and are important for the induction of inflammatory responses, mediated mainly by preformed granular components such as chemokines, cytokines, growth factors, and microbicidal proteins. ${ }^{13-15)}$ After platelet activation, these mediators and newly synthesized eicosanoids influence wound surveillance, repair, and vascular remodeling by signaling target cells and inducing leukocyte accumulation. Recently, Lindemann et al. demonstrated that resting platelets contain numerous mRNAs and the activated platelets contain those translates, such as interleukin (IL)- $1 \beta .^{16}$ ) It was also demonstrated that this process continues for hours after stimulation with thrombinor integrin-mediated adhesion. It was also reported that human platelets bind to phagocytes via P-selectin and P-selectin glycoprotein ligand-1 (PSGL-1) and modulate the function of these cells, i.e., by cytokine production, superoxide anion production, etc. ${ }^{17-20)}$

Elstad et al. suggested that P-selectin primes monocytes for increased platelet-activating factor (PAF) synthesis through regulation of the $\beta$-glucan receptor or regulation of signal transduction mechanisms that are linked to the receptor, and that P-selectin expressed on endothelial cells or platelets may serve both to localize monocytes at sites of vascular inflammation or thrombosis and to prime the cells for subsequent responses to augment inflammation. ${ }^{21)}$ These suggest the possibility that human platelets contribute to the induction of various immunopharmacological activities of fungal $(1 \rightarrow 3)$ - $\beta$-D-glucans and to the enhancement of inflammatory responses.

Recently, we have demonstrated that human leukocytes as well as cell lines were activated in vitro by a $\beta$-glucan preparation, schizophyllan (SPG), to produce IL-8. The activity was also shown in whole-blood cultures. ${ }^{8,22}$ The activity was obvious with both SPG and its single-helical conformer SPG-OH and was confirmed by increased expression of mRNA. Thus in this study, we examined the effect of human platelets on cytokine production from human leukocytes stimulated with SPG. Some of the immunostimulatory activities of SPG are significantly dependent on the conformation, i.e., triple helix (SPG) and single helix (SPG-OH) ${ }^{23)}$ and thus the conformation dependency of the reaction was also examined. 


\section{MATERIALS AND METHODS}

Materials SPG was generously provided by Kaken Pharmaceutical Co., Ltd. (Tokyo, Japan). The single-helix conformer of SPG (SPG-OH) was prepared by dissolving in $0.5 \mathrm{~N} \mathrm{NaOH}$ and dialysis in physiologic saline. ${ }^{23)}$ Fetal calf serum (FCS) was purchased from ATLANTA Biologicals. RPMI 1640 medium was purchased from Sigma Chemical Co. Recombinant human IL-8 was purchased from Pharmingen.

Preparation of Human Peripheral Blood Leukocytes Peripheral blood mononuclear cells (PBMCs) and polymorphonuclear leukocytes (PMNs) were obtained from healthy volunteers. The blood was centrifuged $\left(3000 \mathrm{rpm}\right.$ at $4{ }^{\circ} \mathrm{C}$ for $10 \mathrm{~min}$ ) to obtain the leukocyte-rich fraction. The fraction was mixed well with an equal volume of phosphate-buffered saline (PBS) and centrifuged on $6 \mathrm{ml}$ of HISTOPAQUE (density 1.077 and 1.119; Sigma Chemical Co., U.S.A.) in a 15$\mathrm{ml}$ centrifuge tube (Falcon 352196, Becton Dickinson, Lincoln Park, NJ, U.S.A.) at $2500 \mathrm{rpm}$ for $25 \mathrm{~min}$ at room temperature. After centrifugation, isolated PBMCs and PMNs were washed three times with PBS and cultured in polypropylene tubes (Iwaki Glass, Japan) in $1 \mathrm{ml}$ of RPMI 1640 medium (Nissui Seiyaku Co.) supplemented with $N$-hydroxyethylpiperazin- $N^{\prime}$-2-ethanesulfonate (HEPES, $5 \mathrm{~mm}$ ), penicillin $\mathrm{G}(100 \mathrm{U} / \mathrm{ml})$, and streptomycin $(100 \mu \mathrm{g} / \mathrm{ml})$ containing $10 \%$ autologous serum in culture tubes at $37^{\circ} \mathrm{C}$ in humidified $5 \% \mathrm{CO}_{2}$.

Preparation of Human Platelets Platelets were isolated using the methods of Hamburger and McEver. ${ }^{24)}$ In brief, human blood was drawn into acid-citrate-dextrose (ACD, Sigma Chemical Co.) and centrifuged $(200 \times \boldsymbol{g}$ for $20 \mathrm{~min})$ to obtain platelet-rich plasma. Platelet-rich plasma was recentrifuged $(500 \times \boldsymbol{g}$ for $20 \mathrm{~min})$ in the presence of $100 \mathrm{~nm}$ prostagrandin E-1 (PGE-1, Sigma Chemical Co.). ${ }^{25)}$ The supernatant was discarded and $50 \mathrm{ml}$ of Pipes/saline/glucose (5 mm Pipes, $145 \mathrm{~mm} \mathrm{NaCl}, 4 \mathrm{~mm} \mathrm{KCl}, 50 \mu \mathrm{M} \mathrm{Na}_{2} \mathrm{HPO}_{4}$, $1 \mathrm{~mm} \mathrm{MgCl}{ }_{2}-6 \mathrm{H}_{2} \mathrm{O}$, and $5.5 \mathrm{~mm}$ glucose) containing $100 \mathrm{~nm}$ of PGE-1 was used to resuspend the platelet pellet. The platelet suspension was centrifuged $(500 \times \boldsymbol{g}$ for $20 \mathrm{~min})$, the supernatant was discarded, and the platelet pellet was resuspended in RPMI 1640 medium.

Human Peripheral Blood Leukocyte Cell Culture In vitro cell culture was performed using methods similar to those reported in previous publications from our laboratory. ${ }^{822)}$ Briefly, human PBMCs and PMNs $\left(1.0 \times 10^{5} / \mathrm{ml}\right)$ were cultured with human platelets $\left(1.0 \times 10^{7} / \mathrm{ml}\right)$ in the presence or absence of SPG or SPG-OH $(100 \mu \mathrm{g} / \mathrm{ml})$ at $37^{\circ} \mathrm{C}$ for $18 \mathrm{~h}$. After incubation, the supernatant was obtained.

ELISA for IL-8 A 96-well plate (Sumitomo Bakelite Co., Tokyo, Japan) was coated with anti-human IL-8 monoclonal antibody (Pharmingen, CA, U.S.A.) in $0.1 \mathrm{~m}$ bicarbonate buffer ( $\mathrm{pH}$ 9.6) by incubation at $4{ }^{\circ} \mathrm{C}$ overnight. The plate was washed with PBS containing $0.05 \%$ Tween 20 (Wako Pure Chemical Co.) (PBST) and blocked with $0.5 \%$ bovine serum albumin (Sigma Chemical Co.) (BPBST) at $37^{\circ} \mathrm{C}$ for $40 \mathrm{~min}$. After washing, the plate was incubated with $50 \mu \mathrm{l}$ of recombinant human IL- 8 or samples at $37^{\circ} \mathrm{C}$ for $40 \mathrm{~min}$. The plate was washed three times with PBST and then treated with biotinylated anti-human IL-8 polyclonal antibody (Pharmingen) at $37^{\circ} \mathrm{C}$ for $40 \mathrm{~min}$. After the incubation, the plate was treated with streptavidin-peroxidase and tetramethylbenzidine (TMB) substrate system (KPL Inc., MD, U.S.A.). Color development was stopped with $1 \mathrm{~N}$ phosphoric acid and the optimal density at $450 \mathrm{~nm}$ was measured using a microplate reader (Corona Electric Co., Ltd.).

Flow Cytometric Analysis of P-Selectin Expressed on Human Platelets Stimulated with SPG Platelets were prepared as described above and incubated with SPG at $37^{\circ} \mathrm{C}$ for $2 \mathrm{~h}$. After incubation, platelets were washed three times with PBS, and fluorescein isothiocyanate (FITC)-conjugated anti-human P-selectin (R \& D System) was added. Expression of P-selectin on human platelets was measured using FACS Calibur (Becton-Dickinson).

Statistical Analysis All experiments were performed in triplicate. The data are expressed as mean \pm S.D. Significance was evaluated using Student's $t$-test; $p<0.05$ was considered significant.

\section{RESULTS}

Effect of Human Platelets on IL-8 Production of PBMCs and PMNs Stimulated with SPG and SPG-OH We investigated the effect of human platelets on IL-8 production by PBMCs and PMNs in the presence or absence of SPG and SPG-OH. The optimum dose of SPG/SPG-OH $(100 \mu \mathrm{g} / \mathrm{ml})$, established in previous experiments without
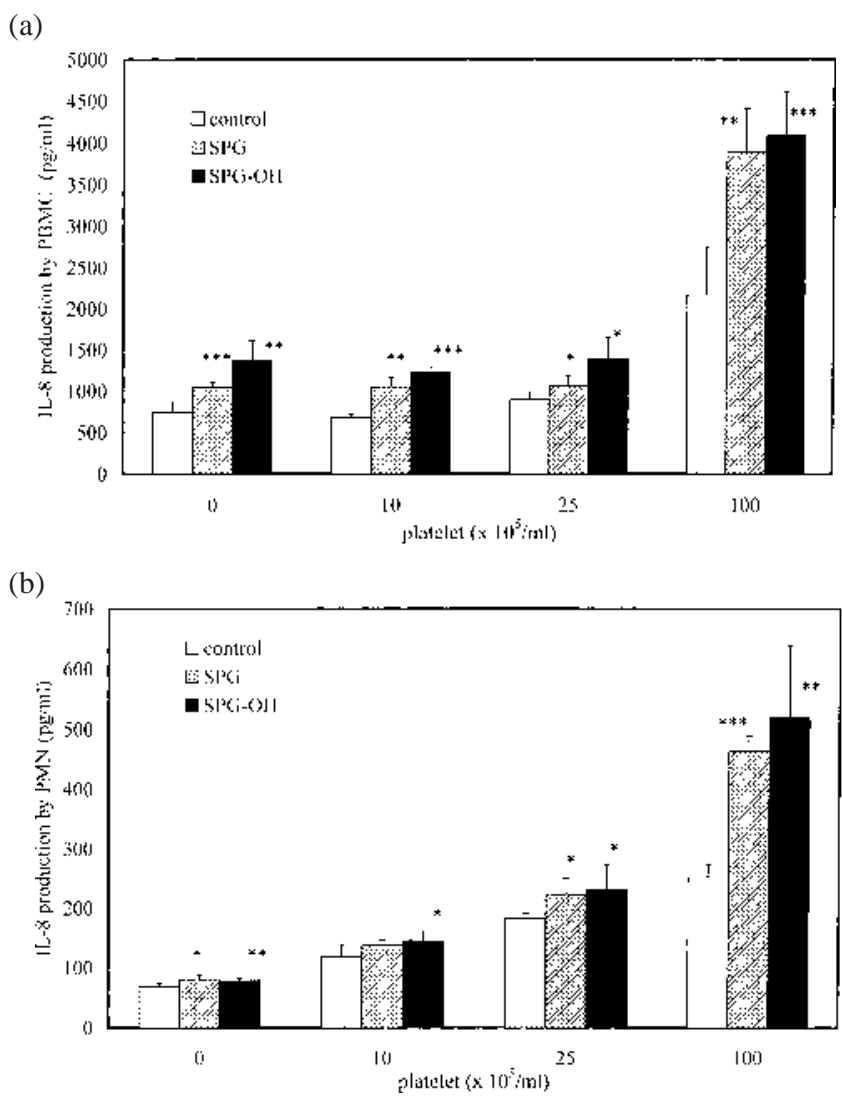

Fig. 1. Concentration Dependency of Human Platelets on IL-8 Production by Human Peripheral Blood Mononuclear Cells and Polymorphonuclear Cells in the Presence of SPG and SPG-OH

Human PBMCs (a) and PMNs (b) were cultured with $1.0 \times 10^{6}, 2.5 \times 10^{6}$ or $1.0 \times 10^{7}$ cells $/ \mathrm{ml}$ of human platelets at $37^{\circ} \mathrm{C}$ for $18 \mathrm{~h}$ in the presence or absence of SPG/SPG$\mathrm{OH}$. After incubation, IL-8 activity in culture supernatant was measured using ELISA. $* p<0.05, * * p<0.01, * * * p<0.001$ ( $v s$. corresponding control). 


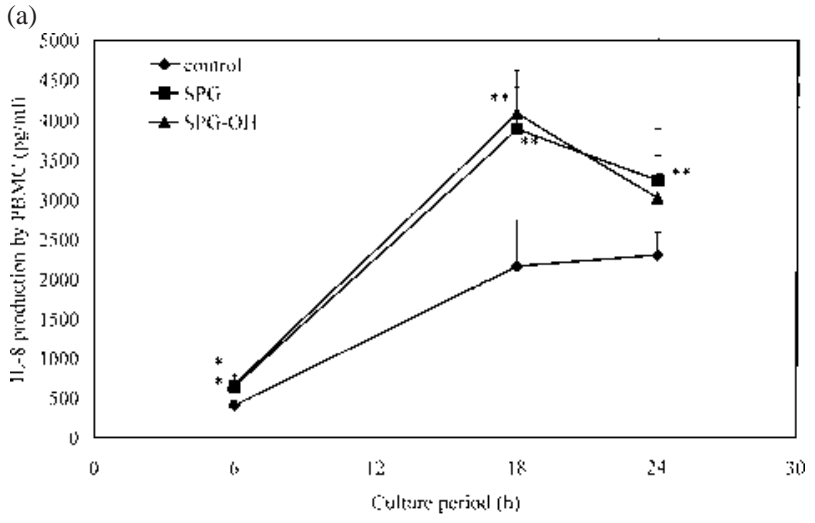

(b)

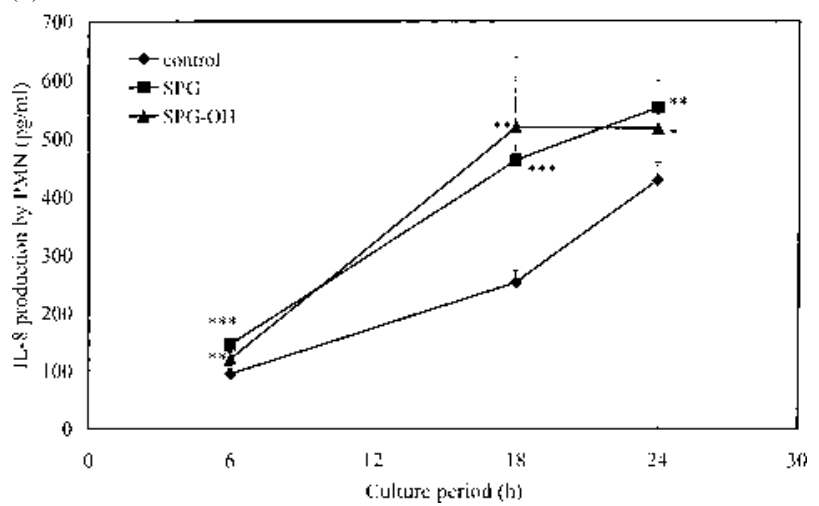

Fig. 2. Incubation Time Dependency on IL-8 Production by Human Peripheral Blood Mononuclear Cells and Polymorphonuclear Cells Stimulated with SPG/SPG-OH and Human Platelets

Human PBMCs (a) and PMNs (b) were cultured with $1.0 \times 10^{7}$ cells $/ \mathrm{ml}$ of human platelets at $37^{\circ} \mathrm{C}$ for 6,18 , and $24 \mathrm{~h}$ in the presence or absence of SPG/SPG-OH. After incubation, IL-8 activity in culture supernatant was measured using ELISA. $* p<0.05$, $* * p<0.01, * * * p<0.001$ (vs. corresponding control).

platelets, was added to the culture and incubated. ${ }^{8,22)}$ IL-8 production by PBMCs (Fig. 1a) and PMNs (Fig. 1b) stimulated with SPG/SPG-OH in the presence or absence of human platelets was enhanced in a platelet concentration-dependent manner. SPG/SPG-OH showed statistically significant activity without platelets as previously reported, although, the production of IL-8 was significantly enhanced in the presence of platelets. In this experimental protocol, the strongest activity was obtained in the presence of $1 \times 10^{7}$ platelets/ml stimulated by both SPG and SPG-OH. It is of note that IL-8 production by the control culture with platelets in the absence of SPG/SPG-OH was also enhanced dose dependently.

Using the optimum concentration of platelets, the kinetics of IL-8 production were examined. IL-8 production reached the maximal level at $18 \mathrm{~h}$ of incubation in the presence of both SPG and SPG-OH (Figs. 2a, b). These results strongly suggest that platelets significantly modulate the cytokine production of PBMCs and PMNs stimulated with SPG/SPG$\mathrm{OH}$. In addition, in this experimental system, the conformation of SPG did not significantly modulate the activity.

Effect of SPG/SPG-OH-Treated Human Platelets on IL-8 Production by Human PBMCs As mentioned above, IL-8 production by PBMCs and PMNs stimulated with SPG/SPG-OH was augmented by coculture with platelets. As shown in Fig. 1, SPG stimulated IL-8 production by PBMCs

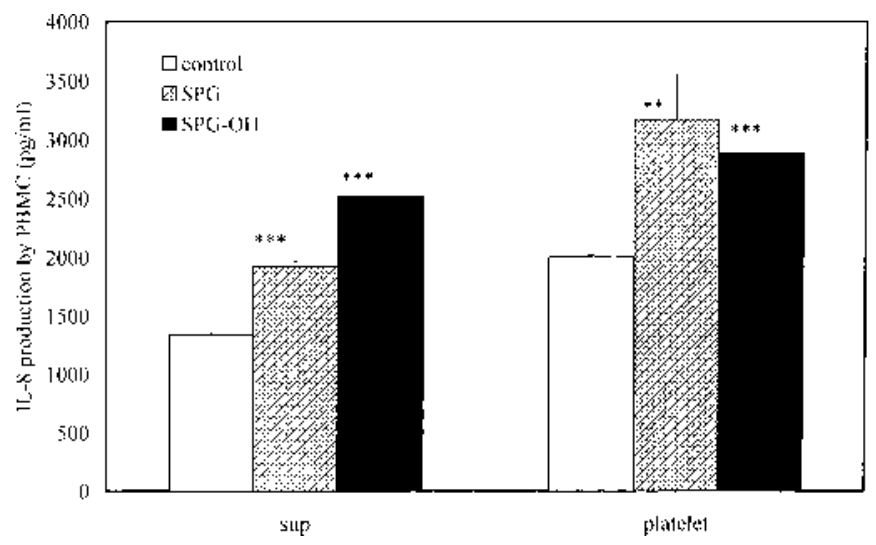

Fig. 3. Effect of Human Platelets Stimulated with SPG/SPG-OH on IL-8 Production by Human Peripheral Blood Mononuclear Cells

Human platelets were cultured with SPG/SPG-OH at $37^{\circ} \mathrm{C}$ for $2 \mathrm{~h}$. The resulting platelets or culture supernatant (sup) was added to human PBMCs, and the mixture was incubated at $37^{\circ} \mathrm{C}$ for $18 \mathrm{~h}$. IL- 8 production was measured using ELISA. $* * p<0.01$, $* * * p<0.001$ ( $v s$. corresponding control).

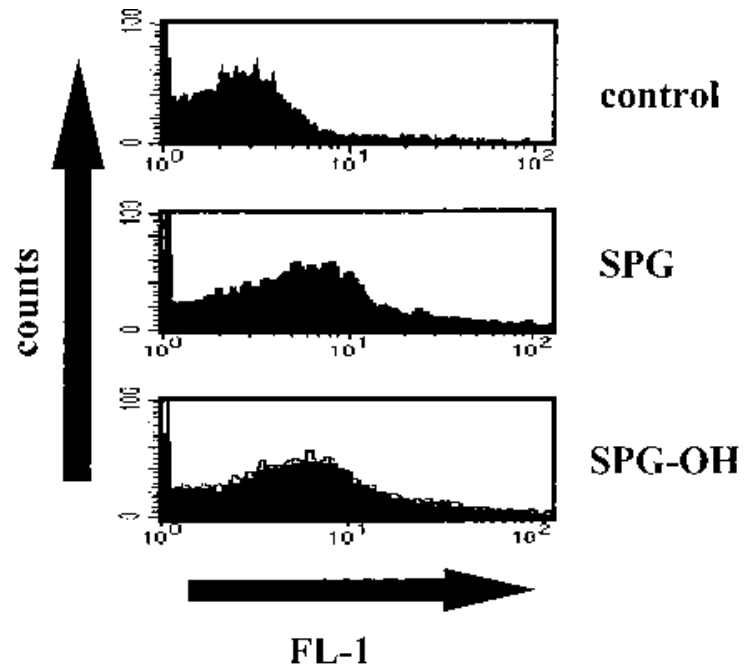

Fig. 4. Flow Cytometry of P-selectin on Human Platelets

Human platelets were incubated with SPG/SPG-OH at $37^{\circ} \mathrm{C}$ for $2 \mathrm{~h}$. The resulting platelets were washed with PBS, and the expression of P-selectin was measured using flow cytometry. In the control group, saline was added instead of SPG.

without platelets, and platelets stimulated IL-8 production of PBMCs without SPG/SPG-OH. To clarify the effect of SPG/SPG-OH on platelets, platelets were first treated with SPG/SPG-OH, the treated platelets and culture supernatants were added to PBMCs and IL-8 production was monitored. Platelet suspensions were treated with SPG/SPG-OH for $2 \mathrm{~h}$ and then the SPG-treated platelets and culture supernatants were added to PBMCs and cultured for $18 \mathrm{~h}$. SPG-treated platelets and culture supernatants enhanced the IL-8 production by PBMCs, and the activity in SPG-treated platelets was slightly stronger than that in culture supernatants (Fig. 3). These results strongly suggest that SPG/SPG-OH directly activates platelets within $2 \mathrm{~h}$ of culture, and that secreted materials, such as eicosanoids, as well as cellular components contribute to the IL-8 production by leukocytes.

Expression of P-Selectin on SPG/SPG-OH-Treated Human Platelets Recently, it has been reported that P-selectin enhances the chemokine production of phagocytes. ${ }^{18)}$ As mentioned above, we found that SPG/SPG-OH enhanced 
the platelet-mediated IL-8 production by PBMCs. Thus we examined the expression of P-selectin on human platelets stimulated with SPG/SPG-OH. Human platelets were cultured with $100 \mu \mathrm{g} / \mathrm{ml}$ of SPG/SPG-OH, and the expression of $\mathrm{P}$-selectin was measured by flow cytometric assay. SPG/SPG$\mathrm{OH}$ enhanced the expression of $\mathrm{P}$-selectin after incubation at $37^{\circ} \mathrm{C}$ for $2 \mathrm{~h}$ (Fig. 4 ).

\section{DISCUSSION}

Platelets are anucleate cells derived from bone marrow megakaryocytes and circulate in the blood. The major function of platelets is to bind to exposed subendothelial matrix at sites of vascular injury to form hemostatic barriers and limit bleeding. In contrast, coagulation mediated by platelet activation, especially intravascular coagulation, is critically important in some diseases, such as atherosclerosis and syndromes of pathologic thrombosis. Platelet hemostatic responses involve activation by the coagulation protein thrombin, which is recognized by a cell surface receptor, or by other agonists. This results in a rapid and complex series of events that includes changes in the shape of the platelets, inside-out signaling of integrins, the release of preformed or internalized proteins from subcellular granules, and generation of eicosanoids by constitutive enzymes. ${ }^{26,27)}$

Three specific granule populations exist in platelets and store different types of constituents. ${ }^{28,29)}$ During circulation, platelets are reactive to various stimuli and release the materials stored in the specific granules. This "release reaction" is an important step in primary hemostasis. Each granule population has specific properties concerning both the structure and the role played by the released constituents. Dense granules contain small nonprotein molecules that are secreted to recruit other platelets. Alpha-Granules contain large adhesive and healing proteins. Lysosomes contain hydrolases able to eliminate the circulating platelet aggregate. Upon activation of platelets, the contents of storage granules are released to the environment and modulate local functions.

In addition, at least a part of their functions are mediated through protein synthesis of platelets. Recently, it has been found that resting platelets contain mRNA of various proteins and they are translated upon activation. ${ }^{30)}$ Lindemann et al. have recently demonstrated that resting platelets contain mRNAs for various proteins in polysomes, such as IL- $1 \beta$ precursor, and are translated by activation. ${ }^{16)}$ A portion of the IL- $1 \beta$ is shed in its mature form in membrane microvesicles and induces adhesiveness of human endothelial cells for neutrophils.

Weyrich et al. demonstrated that activated platelets induce secretion of monocyte chemotactic protein-1 (MCP-1) and IL-8 by monocytes, and that adhesion via P-selectin is required for these responses. ${ }^{18)}$ Rather than directly triggering these events, P-selectin acts in concert with RANTES, a chemokine that is stored and released by activated platelets, ${ }^{18)}$ i.e., MCP-1 production of monocytes by platelets is inhibited by anti-RANTES antibody. ${ }^{18)}$ These results are closely related to the findings shown in the present study. We found that IL-8 synthesis by PBMCs and PMNs stimulated with SPG/SPG-OH was accompanied by enhanced P-selectin expression (Fig. 4). Both the soluble and particulate fractions of SPG-treated platelets are effective for IL- 8 synthesis by
PBMCs. In this experimental system, the soluble fraction might supply RANTES and the particulate fraction supply Pselectin.

Elstad et al. reported that zymosan-mediated PAF production was enhanced by stimulation with P-selectin, ${ }^{21)}$ and that $\mathrm{P}$-selectin might modulate the function of the $\beta$-glucan receptor. These results strongly suggest that $\mathrm{P}$-selectin induces the expression of functional $\beta$-glucan receptor on phagocytes and that fungal $(1 \rightarrow 3)-\beta$-D-glucans induce the expression of $\beta$-glucan receptor indirectly via the activation of platelets. However, only weak P-selectin expression by platelets was observed in this experimental system (Fig. 4), and thus other factors might also contribute to the mechanism. Platelets release of chemokines may be one such role, i.e., RANTES is a major chemokine released from concentrated platelet preparation for transfusion and thus might be present in higher concentrations in the SPG-treated supernatant. ${ }^{31)}$ Furthermore, it is reported that IL- 8 receptor exists on platelets. ${ }^{32}$ ) Therefore SPG/SPG-OH-mediated IL- 8 synthesis by leukocytes may be due to the synergistic action of the secreted products, RANTES, and membranous receptor, P-selectin, of platelets as well as released IL- 8 .

Fungal $(1 \rightarrow 3)$ - $\beta$-D-glucans possess various immunomodulating activities, and one of them, SPG, is clinically used as a immunopotentiator against leukocytepenia. Our series of investigations strongly suggests that the conformation of the $\beta$ glucan is important for the characteristics of immunopharmacological activity. The triple-helix form of SPG and the single-helix form of SPG-OH exhibit significantly different properties depending on the assay used, i.e., nitric oxide synthesis by macrophages was only observed with SPG-OH, but enhanced hematopoietic activity in cyclophosphamide-induced leukopenia was seen with both SPG and SPG-OH. In the present study, platelet activation was observed similarly with both SPG and SPG-OH. These results strongly suggest the activation is conformation independent.

It is well known that soluble $(1 \rightarrow 3)-\beta$-D-glucans are detected in the serum of patients with systemic fungal infections. ${ }^{9)}$ It is also sometimes high in patients on hemodialysis. Although the role of released $\beta$-glucans is not understood, there is a possibility that released $\beta$-glucans as well as clinically used $\beta$-glucans have immunomodulating activities. On the other hand, $\beta$-glucans have several toxic activities, such as a lethal effect in combination with indomethacin and pulmonary granulomatous vasculitis. ${ }^{33-36)}$ It is not known whether released $\beta$-glucans improve the clinical symptoms of systemic fungal infections by modulation of the immune system. However, the data shown in this study include an additional immunostimulating mechanism via platelets activated by $(1 \rightarrow 3)-\beta$-D-glucan. $\beta$-Glucans of the pathogenic fungi might share these mechanisms at least in part.

\section{REFERENCES}

1) Klis F. M., Yeast, 10, 851-869 (1994).

2) Cid V. J., Duran A., del Rey F., Snyder M. P., Nombela C., Sanchez M., Microbiol. Rev., 59, 345-386 (1995).

3) Fujimoto S., Orita K., Kondoh T., Taguchi T., Yoshida K., Kimura T., Ogawa N., Furue H., Biotherapy, 2, 509-521 (1988).

4) Suzuki T., Ohno N., Saito K., Yadomae T., J. Pharmacobio-Dyn., 15, 277-285 (1992).

5) Sakurai T., Ohno N., Yadomae T., J. Leukoc. Biol., 60, 118-124 (1996). 
6) Ohno N., Hashimoto T., Adachi Y., Yadomae T., Immunol. Lett., 53, 157-163 (1996).

7) Yadomae T., Ohno N., Rec. Res. Devel. Chem. Pharm. Sci., 1, 23-33 (1996).

8) Hirata N., Tsuzuki A., Ohno N., Saita M., Adachi Y., Yadomae T., Zentralbl. Bakteriol., 288, 403-413 (1998).

9) Obayashi T., Yoshida M., Mori T., Goto H., Yasuoka A., Iwasaki H., Teshima H., Kohno S., Horiuchi A., Ito A., Yamaguchi H., Shimada K., Iwanaga S., Lancet, 345, 17-20 (1995).

10) Czop J. K., Austen K. F., J. Immunol., 133, 2588-2593 (1985).

11) Konopski Z., Rasmussen L. T., Seljelid R., Eskeland T., Scand. J. Immunol., 33, 297-306 (1991).

12) Szabo T., Kadish J. L., Czop J. K., J. Biol. Chem., 270, 2145-2151 (1995).

13) Yeaman M. R., Ibrahim A. S., Edwards J. E., Bayer A. S., Ghannoum M. A., Antimicrob. Agents Chemother., 37, 546-553 (1993).

14) Dankert J., van der Werff J., Zaat S. A., Joldersma W., Klein D., Hess J., Infect. Immun., 63, 663-671 (1995).

15) Mannaioni P. F., Di Bello M. G., Masini E., Inflamm. Res., 46, 4-18 (1997).

16) Lindemann S., Tolley N. D., Dixon D. A., McIntyre T. M., Prescott S. M., Zimmerman G. A., Weyrich A. S., J. Cell Biol., 154, 485-490 (2001).

17) Tsuji T., Nagata T., Koike K., Todoroki K., Irimura N., J. Leukoc. Biol., 56, 583-587 (1994).

18) Weyrich A. S., Elstad M. R., McEver R. P., McIntyre T. M., Moor K. L., Morrissey J. H., Prescott S. M., Zimmerman G. A., J. Clin. Invest., 97, 1525-1534 (1996).

19) Weyrich A. S., McIntyre T. M., McEver R. P., Prescott S. M., Zimmerman G. A., J. Clin. Invest., 95, 2297-2303 (1995).

20) Cooper D., Butcher C. M., Bredt M. C., Vadas M. A., J. Immunol., 153, 3199-3209 (1994).
21) Elstad M. R., La Pine T. R., Cowley F. S., McEver R. P., McIntyre T. M., Prescott S. M., Zimmerman G. A., J. Immunol., 155, 2109-2122 (1995).

22) Tsuzuki A., Ohno N., Adachi Y., Yadomae T., Drug Develop. Res., 48, $17-25$ (1999).

23) Hashimoto T., Ohno N., Adachi Y., Yadomae T., FEMS Immunol. Med. Microb., 19, 131-135 (1997).

24) Hamburger S. A., McEver R. P., Blood, 75, 550-554 (1990).

25) Butenas S., Cawthern K. M., van't Veer C., DiLorenzo M. E., Lock J. B., Mann K. G., Blood, 97, 2314-2322 (2001).

26) Shivdasani R. A., Stem Cells, 19, 397-407 (2001).

27) Blockmans D., Deckmyn H., Vermylen J., Blood Rev., 9, 143-156 (1995).

28) Rendu F., Brohard-Bohn B., Platelets, 12, 261-273 (2001)

29) Chen D., Lemons P. P., Schraw T., Whiteheart S. W., Blood, 96, $1782-1788$ (2000).

30) Weyrich A. S., Dixon D. A., Pabla R., Elstad M. R., McIntyre T. M., Prescott S. M., Zimmerman G. A., Proc. Natl. Acad. Sci. U.S.A., 95, 5556-5561 (1998).

31) Bubel S., Wilhelm D., Entelmann M., Kirchner H., Kluter H., Transfusion, 36, 445-449 (1996).

32) Power A. C., Clemetson J. M., Clemtson K. J., Wells T. N. C., Cytokine, 7, 479-482 (1995).

33) Yoshioka S., Ohno N., Miura T., Adachi Y., Yadomae T., FEMS Immunol. Med. Microbiol., 21, 171-179 (1998).

34) Iwamoto N., Yoshioka T., Nitta K., Ito K., Life Sci., 62, 247-255 (1998).

35) Barton P. A., Imaley M. M., Flory C. M., Warren J. S., J. Lab. Clin. Med., 128, 181-193 (1996).

36) Sortwell R. J., Dawe S., Allen D. G., Street A. E., Heywood R., Edmondson N. A., Gopinath C., Toxicol. Lett., 9, 81-85 (1981). 